\title{
Predictors of Very-Low-Energy Diet Outcome in Obese Women and Men
}

\author{
Lena Gripeteg $^{\mathrm{a}, \mathrm{b}} \quad$ Jan Karlsson $^{\mathrm{c}} \quad$ Jarl Torgerson ${ }^{\mathrm{a}, \mathrm{d}} \quad$ Anna Karin Lindroos ${ }^{\mathrm{e}}$ \\ ${ }^{a}$ Department of Molecular and Clinical Medicine, Institute of Medicine, The Sahlgrenska Academy, University of Gothenburg, Göteborg, \\ ${ }^{\mathrm{b}}$ Vårdalinstitutet, Lund, \\ 'Institute of Health and Care Sciences, The Sahlgrenska Academy, University of Gothenburg, Göteborg, \\ ${ }^{d}$ Department of Health Care, Regional Secretariat, Göteborg, Sweden \\ ${ }^{\mathrm{e}}$ MRC Human Nutrition Research, Cambridge, UK
}

\section{Keywords}

Obesity · Weight loss $\cdot$ VLCD $\cdot$ Outcome .

Predictive factors

\section{Summary}

Objective: The aim of this study was to explore baseline outcome predictors of a 12-week very-low-energy diet (VLED) treatment. Methods: Obese patients (177 women and 90 men) started treatment. Multivariate linear and logistic regressions were used to predict weight loss (\%), successful outcome ( $\geq 10 \%$ weight loss) and attrition. Potential predictors were anthropometry, socioeconomic variables, established questionnaires on health-related quality of life, and eating behavior, and additional questions related to dieting. Results: Mean weight loss was $13.5 \%$ (standard deviation (SD) 5.6 ) in women and $15.1 \%$ (6.1) in men ( $p=0.054)$. Greater weight loss in women was predicted by having more children, lower education, and better perceived physical health (R-square $\left(R^{2}\right)=$ $12.7 \%)$, and in men by better ambulation capacity, living with a partner/children, and snacking on ice-cream more often $\left(R^{2}=39.4 \%\right)$. Successful outcome in women was predicted by less obesity-related psychosocial dysfunction, and in men by better functioning in social interaction and ambulation capacity. Attrition was predicted by lower age and larger hip circumference in women, and in men by lower perceived general health. Two-week weight loss was independently associated with all outcomes except attrition in women. Conclusion: Factors related to perceived physical health, social interaction, socio-economic factors, and obesity-related psychosocial problems predicted VLED outcome. The predictors differed by gender.

\section{Introduction}

Very-low-energy diets (VLEDs) can be used to obtain substantial weight loss during a limited treatment period [1]. VLEDs are generally used in obese patients but can also be a treatment option in overweight subjects with associated comorbidity. Contraindications for VLED treatment include pregnancy, diabetes type 1 , severe renal, hepatic, cardiac, and cerebrovascular disease, catabolic disorders including malignancies, as well as severe psychiatric disorders including bulimia and drug abuse. The energy content of a VLED equals $450-800 \mathrm{kcal} /$ day. VLEDs are relatively enriched in protein, fulfil recommended daily allowances for vitamins, minerals, electrolytes, and essential fatty acids, and are mainly provided as liquid diets. Weekly weight loss equals $1.5-2.5 \mathrm{~kg}$ [1] with parallel improvements in physical and psychosocial functioning [2]. The risk factor response is rapid, and VLEDs are therefore particularly beneficial in patients with obesityrelated co-morbidity [3]. The fundamental advantage of VLEDs is the unambiguousness in food choice, making dietary adherence relatively easy, in theory. In addition, the very restrictive liquid diet intensifies the decrease in food cravings more than a moderately energy-reduced ordinary diet [4]. Both these factors could improve VLED adherence, compared with the often poor compliance seen when using foodbased low energy diets [5]. However, while some patients find it convenient to follow a VLED, others will face problems. The monotonous liquid formula may lead to diet aversion and poor compliance. Although some studies report no medical complications [6], others have observed minor side effects such as dizziness [7, 8], gastrointestinal symptoms [7-9], coldness [8], anxiety, and asthenia [9]. Potentially severe side effects of VLED treatment include gallstones and gout [1]. At-

\section{KARGER}

Fax +497614520714

Information@Karger.de

www.karger.com (c) 2010 S. Karger GmbH, Freiburg

Accessible online at:

www.karger.com/ofa
Lena Gripeteg

Department of Molecular and Clinical Medicine, Institute of Medicine

The Sahlgrenska Academy, University of Gothenbur

Vita Stråket 15, 41345 Göteborg, Sweden

Tel. +46 31-3426735 Fax -418527

lena.gripeteg@invmed.gu.se. 
trition rates between 7 and $28 \%$ have also been reported in VLED programs ranging from 10 to 12 weeks [4, 10-14].

Identifying weight loss predictors is crucial for improving the management of obesity [15]. Larger initial weight loss has been associated with better weight loss long term [16-18], which is the reason why we have conducted several clinical trials trying to optimise VLED treatment [19-23]. VLED treatment that does not lead to the expected weight loss may on the other hand be stressful for the patient and is also a potential waste of clinical resources. Therefore, it is important to understand which patients are most likely to benefit from VLED treatment and to identify those who need extra support. Therefore, the aim of this study was to explore possible baseline outcome predictors of a 12-week VLED treatment.

\section{Material and Methods}

\section{Patient Selection}

Between August 2004 and January 2007, 600 patients were referred to the Obesity Unit at Sahlgrenska University Hospital. The Obesity Unit could offer referred patients different treatment options including life style modification, VLED, weight loss medication, and obesity surgery depending on individual preferences and medical requirements. These treatment options were either part of randomized clinical trials or included in routine clinical care. Patients in this study were recruited to participate in a 1-year structured obesity intervention with 12 weeks initial VLED [22]. In total, 300 patients were enrolled in the trial. However, 22 subjects never completed the baseline questionnaires and 11 never started treatment, leaving 267 patients for the following analyses. Referred subjects were eligible for the present trial if aged 18-60 years with a body mass index (BMI) $>30.0 \mathrm{~kg} / \mathrm{m}^{2}$ and meeting the criteria for VLED treatment based on current guidelines [1]. All participants had to pass an initial medical and dietary examination to identify possible contraindications for VLED treatment including pregnancy and lactation, unstable type 1 diabetes, cardiac disease, recent cerebrovascular disease, history of eating disorder, severe psychiatric disorder, or other severe disease. Concomitant weight loss medication was not allowed. The study was approved by the regional ethical review board, and all participants gave written informed consent.

\section{Treatment Program}

During the 12-week treatment period, patients were encouraged to follow a strict liquid VLED (470-820 kcal). They selected and paid for one of the following: Modifast $^{\oplus}$ (Novartis, Basel, Switzerland; $820 \mathrm{kcal}, \mathrm{n}=212$ ), Nutrilett $^{\circledR}$ (Nycomed Pharma, Oslo, Norway; $560 \mathrm{kcal}, \mathrm{n}=13$ ), or Cambridgekuren ${ }^{\circledR}$ (Cambridgekuren, Solna, Sweden; $470 \mathrm{kcal}, \mathrm{n}=40$ ) (total cost 5-7 EUR/day). Information on choice of VLED was not recorded for 2 participants. Free consumption of non-caloric drinks ( $<6 \mathrm{kcal} / 100 \mathrm{~g})$ was allowed. All patients had scheduled visits to an obesity clinic nurse at weeks 0 (baseline), 2, 5, 8, and 12. Body weight was measured at each visit, and patients were given support and counselling to enhance VLED compliance. Side effects were monitored. All patients were encouraged to be physically active.

\section{Baseline Examination}

Anthropometry, Co-Morbidity, and Medication

Body weight was measured on calibrated, electronic scales in underwear and without shoes to the nearest $0.1 \mathrm{~kg}$. Height was measured in standing position to the nearest $0.5 \mathrm{~cm}$. BMI was calculated $\left(\mathrm{kg} / \mathrm{m}^{2}\right)$. Waist circumference was measured midway between the costal arch and the iliac crest, and hip circumference at the symphysis-trochanter femoris level to the nearest $1.0 \mathrm{~cm}$. All measures were performed by trained staff. Information on co-morbidity and prescribed medication was also collected.

\section{Questionnaires}

Patients completed questionnaires on socioeconomic status (SES), eating behavior, and health-related quality of life. SES covered marital status, family structure, education, employment, income, sick leave, and disability pension. Self-assessed eating style and eating behavior were measured by the TFEQ-R21 $[24,25]$ which is a revised, short form of the original 51item Three-Factor Eating Questionnaire (TFEQ). The construct validity of the 51-item TFEQ was investigated in a study of 4,377 obese men and women in Sweden [24]. The original TFEQ factor structure could not be replicated. A short, revised 18-item instrument was developed that covers 3 domains: cognitive restraint, uncontrolled eating, and emotional eating. A further refined 21-item version of the instrument (TFEQ-R21) that includes 3 additional items on emotional eating was used in the present study [25]. The cognitive restraint scale assesses control of food intake in order to influence body weight and body shape. The uncontrolled eating scale assesses the tendency to lose control over eating when feeling hungry or when exposed to external stimuli. The emotional eating scale measures the propensity to overeat in relation to negative mood states, e.g. when feeling lonely, anxious, or depressed. The constructs of cognitive restraint, uncontrolled eating, and emotional eating have been replicated in other studies [26]. Correlations between the original TFEQ scales and the revised, short-form scales have been presented elsewhere [24, 25].

Additional questions on eating behavior, dietary habits, and attitudes toward dieting were constructed for this study. These included 3 questions on perceived hunger: i) in the morning; ii) between meals; and iii) in the evening. Five questions concerned the degree of craving for snack foods. Five groups of snack food were covered: i) sweets; ii) chocolate, nougat, etc.; iii) ice-cream; iv) peanuts, chips/crisps, cheese doodles, etc.; v) buns, cookies/cakes, biscuits, etc. Frequency for each snack food category was assessed on a 5-point scale (never, rarely, sometimes, frequently, always/every day). In addition, summery scores were calculated for snack food cravings and snacking frequency. A 7-item module comprised statements about binge eating, e.g. losing control over eating, eating large amounts of food in a discrete period of time, eating more rapidly than normal, eating until feeling uncomfortably full, and preoccupation with food and eating. Responses to the binge eating items were aggregated to a total score. Two questions comprised motivation to diet (e.g. How motivated are you to lose weight?). Three questions concerned self-efficacy (e.g. How difficult do you think it will be for you to change your ways of living in order to lose weight?). Four statements concerned extrovert or introvert social orientation (e.g. It is easy for me to talk about my weight problems) and social support (e.g. I think I will get support from people around me when I try to lose weight). Responses to items in each domain were aggregated to a total score.

Generic health-related quality of life (HRQL) was assessed by the widely used SF-36 that covers 8 general health status domains: physical functioning, role-physical, bodily pain, general health, vitality, social functioning, role-emotional, and mental health [27]. In addition, a physical and mental component summary score is calculated. The Obesity Functional health scale (OF) was used to assess condition-specific functional limitations [28]. OF comprises 39 items which covers 9 domains: mobility, ambulation, sleep and rest, home management, work, recreation, social interaction, sex life, and aches and pains. An overall functional health score is also calculated. An extended 14-item version of the Obesity-related Problems scale (OP) was used to measure the impact of obesity on psychosocial functioning [29]. Subjects indicate how bothered they are by their obesity in a broad range of social activities. Responses are aggregated to a total score. Mood/mental well-being was measured by the Mood Adjective Check List (MACL). MACL contains 38 adjectives which cover 3 bipolar 
mood dimensions: pleasantness/unpleasantness (e.g. satisfied, optimistic/ depressed, resigned), activation/deactivation (e.g. alert, active/passive, apathetic), and calmness/tension (e.g. relaxed/tensed, distressed) [30]. An overall mood score is also calculated. The Rosenberg Self-Esteem scale (RSE) was used to assess global self-esteem [31]. RSE comprises 10 items, and responses are aggregated to a total score.

\section{Outcome Variables}

We used 3 different outcome variables: percent weight change at week 12 (I), successful versus non-successful outcome at week 12 (II), and attrition during the 12-week VLED (III). VLED treatment was classified as successful if weight reduction after 12 weeks was $\geq 10 \%$ of the initial body weight. Smaller weight loss or attrition was classified as non-successful treatment outcome.

Table 1. Baseline characteristics for women and men $^{\mathrm{a}}$

\begin{tabular}{lcc}
\hline Characteristic & $\begin{array}{l}\text { Women } \\
(\mathrm{n}=177)\end{array}$ & $\begin{array}{l}\text { Men } \\
(\mathrm{n}=90)\end{array}$ \\
\hline Age, years & $40.1 \pm 10.0$ & $40.4 \pm 9.1$ \\
Body weight, kg & $116.0 \pm 20.0^{* * *}$ & $141.9 \pm 25.5$ \\
BMI, kg/m² & $41.2 \pm 6.3^{*}$ & $43.1 \pm 6.5$ \\
Waist circumference, cm & $120.1 \pm 13.2^{* * * *}$ & $135.8 \pm 14.5$ \\
Hip circumference, cm & $130.7 \pm 13.0$ & $129.3 \pm 13.0$ \\
Obesity-related medication ${ }^{\mathrm{b}}, \%$ (n) & $27(47)$ & $31(28)$ \\
Prescribed drugs $\geq 2, \%$ (n) & $57(99)^{*}$ & $42(37)$ \\
Long-term sick leave, \% (n) & $29(52)$ & $24(22)$ \\
Married/living with partner, \% (n) & $69(122)^{*}$ & $52(46)$ \\
Cohabiting with partner/child, \% (n) & $81(143)^{*}$ & $66(58)$ \\
University education, \% (n) & $29(51)^{* *}$ & $15(13)$ \\
Working fulltime, \% (n) & $36(64)^{* * *}$ & $60(54)$ \\
Monthly income, EUR & $1,600 \pm 690^{* * *}$ & $1,960 \pm 890$ \\
\hline
\end{tabular}

${ }^{\mathrm{a}}$ Mean \pm SD or frequencies. The two-sample t-test and the Wilcoxon's two sample test were used for comparison between women and men. ${ }^{\mathrm{b}}$ Obesity-related medication: medication for diabetes/hyperlipidemia/ hypertension.

" $\mathrm{p}<0.05$

$*$ p $<0.01$.

${ }^{* * * *} \mathrm{p}<0.001$.

\section{Analysis and Statistics}

Results are reported as means \pm standard deviation (SD) or as frequencies. All analyses were stratified by sex. Differences between men and women, and between successful and non-successful patients, and between those who dropped-out or not were tested by two-sample t-test (parametric variables) or Wilcoxon two sample test (nonparametric variables). Fisher's exact test was used to compare dichotomous data. Stepwise multivariate regression analyses were used to identify pre-treatment predictors of the 3 outcome variables. Based on initial Pearson correlations (I) or Wilcoxon two sample tests (II and III) independent variables with a p value $\leq 0.1$ were considered as potential predictors in the models and allowed to stay if $\mathrm{p} \leq 0.05$. In addition, the identified predictors and percent weight change at week 2 were tested in multivariate regression models to evaluate the impact of early weight loss on treatment outcome.

\section{Predictors of Percent Weight Change (I)}

Multivariate linear regression was used to identify pre-treatment predictors of weight change in patients who completed 12 VLED weeks. Nineteen and 21 independent variables were entered in the models for women and men, respectively (supplementary information).

\section{Predictors of Successful Outcome (II) and Attrition (III)}

Logistic regression analyses were used to identify variables associated with successful outcome (II) or attrition (III). For VLED success (II), 10 independent variables were entered into the model for women, and 19 for men (supplementary information). Four effect parameters were generated in women, and 5 in men. One from each model was removed due to correlation with other predictors. For attrition (III), 13 variables were entered into the models for both sexes (supplementary information). The logistic analysis output was expressed as an odds ratio with a $95 \%$ confidence interval. All statistical analyses were performed using SAS-PC software, version 8.2 (SAS Institute Inc, Cary, NC, USA).

\section{Results}

Table 1 shows baseline characteristics for men and women separately. Women had a significantly lower body weight $(\mathrm{p}<0.001)$, BMI $(\mathrm{p}<0.05)$, and waist circumference $(\mathrm{p}<0.001)$ than men. A higher proportion of the women had university education $(\mathrm{p}<0.01)$, were married or living to-
Table 2. Independent baseline predictors of percent weight change after 12 weeks of VLED treatment $^{\mathrm{a}}$

\begin{tabular}{lllcc}
\hline & $\beta$-coefficient & Standard error & R-square, \% & p value \\
\hline Women, $n=143^{b}$ & & & & \\
Number of children & 1.02 & 0.43 & 5.6 & 0.004 \\
University education & -2.58 & 0.97 & 3.4 & 0.02 \\
Physical health SF-36 (summary score) ${ }^{\mathrm{c}}$ & 0.0898 & 0.037 & 3.7 & 0.02 \\
Model & & & 12.7 & 0.0003 \\
\hline Men, $n=71^{d}$ & & & & 0.0006 \\
Ambulation capacity OF & 0.092 & 0.024 & 16.0 & 0.0003 \\
Cohabiting with partner/child & 4.75 & 1.2 & 14.5 & 0.003 \\
Snacking on ice cream, frequency & 1.68 & 0.54 & 8.9 & $<0.0001$ \\
Model & & & 39.4 & \\
\hline
\end{tabular}

${ }^{\mathrm{a}}$ Stepwise linear regression analysis.

${ }^{\text {b } T h e ~ m o d e l ~ r e p r e s e n t s ~} 143$ of 148 (96.6\%) female VLED completers due to missing data in the predictive variables. ${ }^{\mathrm{c}}$ Higher scores indicate better physical health.

${ }^{\mathrm{d}}$ The model represents 71 of 73 (97.2\%) male VLED completers due to missing data in the predictive variables. ${ }^{\mathrm{e}}$ Higher scores indicate better functional health. 
gether with a partner or child $(\mathrm{p}<0.05)$, and more women had at least 2 prescribed drugs $(\mathrm{p}<0.05)$. Compared to women, more men worked full time $(\mathrm{p}<0.001)$ and earned a higher income $(\mathrm{p}<0.001)$.

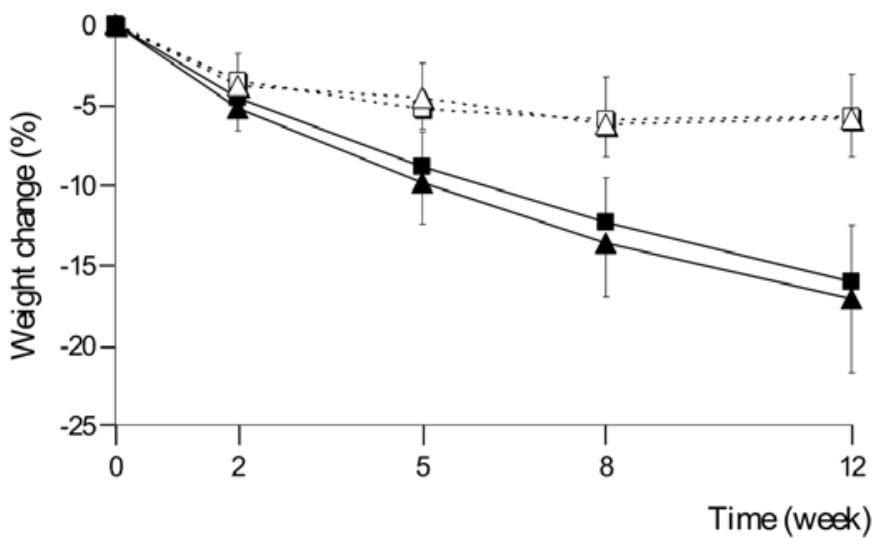

Fig. 1. Percent weight change (mean \pm SD) during 12 weeks of VLED treatment in successful women $(\boldsymbol{\square} ; \mathrm{n}=111)$ and men $(\mathbf{\Delta} ; \mathrm{n}=60)$ and non-successful women $(\square ; \mathrm{n}$ at baseline $=66$; at 12 weeks $=37)$ and men $(\triangle ; \mathrm{n}$ at baseline $=30$; at 12 weeks $=13)$. Successful: $\geq 10 \%$ weight loss after 12 weeks of VLED. Non-successful: VLED attrition or $<10 \%$ weight loss after 12 weeks of VLED.

\section{Predictors of Weight Change (I)}

A total of $148(84 \%)$ women and $73(81 \%)$ men completed the treatment. Mean weight loss after 12 weeks was $13.5 \pm$ $5.6 \%$ and $15.1 \pm 6.1 \%$ in women and men, respectively ( $\mathrm{p}=$ $0.054)$. The independent pre-treatment predictors of relative weight change are shown in table 2 . In women, greater relative weight loss was predicted by having more children, lower educational level, and better perceived physical health (SF-36 Physical health, summary score), $\mathrm{R}^{2}=12.7 \%$. Greater weight loss in men was predicted by better self-assessed ambulatory capacity (OF Ambulation), living with a partner or child, and snacking on ice cream more often, $\mathrm{R}^{2}=39.4 \%$. When entering early weight change (percent weight change at week 2) into the above models, it was independently associated with 12 -week weight loss in both women $(\beta$-coefficient $=1.72$, standard error $(\mathrm{SE})=0.25, \mathrm{p}<0.0001)$ and men $(\beta$-coefficient $=1.57, \mathrm{SE}=0.34, \mathrm{p}<0.0001)$, and $\mathrm{R}^{2}$ increased to 32.4 and $50.3 \%$, respectively. The initial predictors were still significant.

Predictors of Successful Outcome (II)

Success rates did not differ between women and men (63 versus $67 \%, p=0.59)$. At week 12 , weight loss in the successful
Table 3. Baseline characteristics, self-assessed eating behavior, and health-related quality of life (HRQL) in women and men with successful and nonsuccessful VLED treatment outcome $e^{\mathrm{a}, \mathrm{b}}$

\begin{tabular}{|c|c|c|c|c|}
\hline \multirow[t]{2}{*}{ Characteristic } & \multicolumn{2}{|l|}{ Women } & \multicolumn{2}{|l|}{ Men } \\
\hline & $\begin{array}{l}\text { non-successful } \\
(\mathrm{n}=66)\end{array}$ & $\begin{array}{l}\text { successful } \\
(\mathrm{n}=111)\end{array}$ & $\begin{array}{l}\text { non-successful } \\
(\mathrm{n}=30)\end{array}$ & $\begin{array}{l}\text { successful } \\
(\mathrm{n}=60)\end{array}$ \\
\hline Age, years & $37.9 \pm 10.1^{*}$ & $41.5 \pm 9.7$ & $39.5 \pm 8.7$ & $40.9 \pm 9.3$ \\
\hline Body weight, kg & $119.7 \pm 22.1$ & $113.7 \pm 18.4$ & $141.7 \pm 29.0$ & $141.9 \pm 23.8$ \\
\hline $\mathrm{BMI}, \mathrm{kg} / \mathrm{m}^{2}$ & $42.4 \pm 7.0$ & $40.6 \pm 5.8$ & $43.3 \pm 7.3$ & $43.0 \pm 6.1$ \\
\hline Long-term sick leave, \% (n) & $27(18)$ & $31(34)$ & $37(11)$ & $18(11)$ \\
\hline Married/living with partner, \% (n) & $67(44)$ & $70(78)$ & $37(11)^{*}$ & $18(11)$ \\
\hline \multicolumn{5}{|l|}{ Eating behavior TFEQ-R21 ${ }^{\mathrm{c}}$} \\
\hline Cognitive restraint & $43.7 \pm 21.9$ & $45.5 \pm 19.1$ & $35.8 \pm 20.6$ & $37.3 \pm 20.0$ \\
\hline Uncontrolled eating & $46.6 \pm 22.4$ & $44.4 \pm 20.8$ & $52.7 \pm 22.9$ & $37.7 \pm 27.1$ \\
\hline Emotional eating & $60.7 \pm 27.7$ & $60.6 \pm 26.0$ & $52.6 \pm 24.8^{*}$ & $45.6 \pm 21.3$ \\
\hline \multicolumn{5}{|l|}{$\mathrm{HRQL}^{\mathrm{c}}$} \\
\hline Psychosocial functioning OP & $63.3 \pm 20.0^{* * \dagger}$ & $52.5 \pm 24.2$ & $47.9 \pm 27.9$ & $41.2 \pm 25.7$ \\
\hline General health SF-36 & $50.7 \pm 24.9$ & $53.8 \pm 25.3$ & $52.9 \pm 20.1^{*}$ & $62.5 \pm 22.5$ \\
\hline Physical health SF-36 (summary score) & $38.7 \pm 11.0$ & $40.5 \pm 12.3$ & $39.8 \pm 10.4$ & $43.6 \pm 9.6$ \\
\hline Ambulation capacity OF & $60.8 \pm 25.9$ & $62.3 \pm 27.6$ & $59.3 \pm 17.7^{* * *+}$ & $72.6 \pm 24.9$ \\
\hline Social interaction OF & $53.5 \pm 30.0$ & $57.9 \pm 25.2$ & $45.6 \pm 25.4^{* * \dagger}$ & $61.5 \pm 26.4$ \\
\hline Overall mood MACL & $2.6 \pm 0.62$ & $2.6 \pm 0.60$ & $2.6 \pm 0.61$ & $2.8 \pm 0.57$ \\
\hline
\end{tabular}

${ }^{a}$ Non-successful: attrition or $<10 \%$ weight loss after 12 weeks of VLED; successful: $\geq 10 \%$ weight loss after 12 weeks of VLED. ${ }^{b}$ Mean \pm SD or frequencies. The two-sample t-test and the Wilcoxon's two sample test were used for comparison between non-successful and successful women/men.

'The range for all scales is 0-100 except for MACL (scale range 1-4) and SF-36 Physical health summary score (norm-based scoring with 50 as mean for the general population). TFEQ-R21: higher scores represent more restraint, uncontrolled, and emotional eating. OP: higher scores indicate dysfunction. SF-36 General health and MACL: higher scores represent wellbeing. OF Ambulation and Social interaction: higher scores indicate better functional health. SF-36 Physical health: higher scores indicate better physical health.

" $\mathrm{p}<0.05$ between non-successful and successful men.

*** $\mathrm{p}<0.01$ between non-successful and successful women/men.

${ }^{\dagger}$ Variable predicting non-successful/successful outcome. 
Table 4. Baseline characteristics and health-related quality of life (HRQL) in VLED completers and drop-outs ${ }^{\mathrm{a}, \mathrm{b}}$

\begin{tabular}{|c|c|c|c|c|}
\hline \multirow[t]{2}{*}{ Characteristic } & \multicolumn{2}{|l|}{ Women } & \multicolumn{2}{|l|}{ Men } \\
\hline & $\begin{array}{l}\text { attrition } \\
(\mathrm{n}=29)\end{array}$ & $\begin{array}{l}\text { completion } \\
(\mathrm{n}=148)\end{array}$ & $\begin{array}{l}\text { attrition } \\
(\mathrm{n}=17)\end{array}$ & $\begin{array}{l}\text { completion } \\
(\mathrm{n}=73)\end{array}$ \\
\hline Age, years & $34.1 \pm 8.6^{* * \dagger}$ & $41.3 \pm 9.8$ & $37.9 \pm 7.7$ & $41.0 \pm 9.3$ \\
\hline Body weight, kg & $122.8 \pm 19.7^{*}$ & $114.6 \pm 19.8$ & $134.0 \pm 26.4$ & $143.7 \pm 25.1$ \\
\hline $\mathrm{BMI}, \mathrm{kg} / \mathrm{m}^{2}$ & $43.2 \pm 7.0$ & $40.9 \pm 6.1$ & $41.4 \pm 6.1$ & $43.5 \pm 6.16$ \\
\hline Waist circumference, $\mathrm{cm}$ & $122.7 \pm 13.1$ & $119.6 \pm 13.2$ & $130.3 \pm 16.4$ & $137.0 \pm 13.8$ \\
\hline Hip circumference, $\mathrm{cm}$ & $136.0 \pm 12.6^{* \dagger}$ & $129.7 \pm 12.9$ & $127.5 \pm 13.6$ & $129.7 \pm 12.9$ \\
\hline Obesity-related medication, $\%(n)^{\mathrm{c}}$ & $7(2)^{* *}$ & $31(45)$ & $25(4)$ & $33(24)$ \\
\hline Prescribed drugs $\geq 2, \%$ (n) & $34(10)^{* * *}$ & $61(89)$ & $44(7)$ & $41(30)$ \\
\hline \multicolumn{5}{|l|}{ HRQL } \\
\hline Psychosocial functioning OP & $65.3 \pm 18.4^{*}$ & $54.8 \pm 23.8$ & $47.3 \pm 31.6$ & $42.5 \pm 25.3$ \\
\hline General health SF-36 & $52.4 \pm 24.7$ & $52.8 \pm 25.3$ & $46.3 \pm 20.5^{* * \dagger}$ & $62.3 \pm 21.4$ \\
\hline Physical health SF-36 (sum score) & $41.7 \pm 8.9$ & $39.5 \pm 12.3$ & $37.5 \pm 10.6^{*}$ & $43.4 \pm 9.6$ \\
\hline \multicolumn{5}{|c|}{$\begin{array}{l}\text { a'Mean } \pm \text { SD or frequencies. The two-sample t-test and the Wilcoxon's two sample test were used for comparison between } \\
\text { female/male drop-outs and completers. }\end{array}$} \\
\hline \multicolumn{5}{|c|}{$\begin{array}{l}\text { b OP (scale range } 0-100 \text { ): higher scores indicate dysfunction. SF-36 General health (scale range } 0-100 \text { ): higher scores repre- } \\
\text { sent well-being. SF-36 Physical health summary score (norm-based scoring with } 50 \text { as mean for the general population): } \\
\text { higher scores indicate better physical health. }\end{array}$} \\
\hline \multicolumn{5}{|c|}{ 'Obesity-related medication: medication for diabetes/hyperlipidemia/hypertension. } \\
\hline \multicolumn{5}{|c|}{${ }^{*} \mathrm{p}<0.05$ between female/male drop-outs and completers. } \\
\hline \multicolumn{5}{|c|}{${ }^{* *} \mathrm{p}<0.01$ between female/male drop-outs and completers. } \\
\hline \multicolumn{5}{|c|}{${ }^{\dagger}$ Variable predicting treatment attrition/completion. } \\
\hline
\end{tabular}

women was $16.1 \pm 3.5 \%$ and in men $17.1 \pm 4.7 \%$, and in nonsuccessful women and men $5.8 \pm 2.7 \%$ and $5.9 \pm 2.4 \%$, respectively (fig. 1). Selected baseline characteristics, eating behavior, and HRQL variables stratified by outcome are shown in table 3 . The non-successful women were younger $(\mathrm{p}<0.05)$ than the successful women. Compared with successful men, the non-successful men had a lower perceived general health (SF-36 General health) $(\mathrm{p}<0.05)$, more emotional eating (TFEQ-R21) ( $<<0.05)$, and were less likely to be married or living with a partner $(\mathrm{p}<0.05)$. In women, successful outcome was predicted by less obesity-related psychosocial dysfunction (OP) (OR: 0.98, 95\% CI: 0.97-0.999), and in men by better functioning in social interaction (OF Social interaction) (OR: 1.02, 95\% CI: $1.004-1.04$ ) and ambulation capacity (OF Ambulation) (OR: 1.02, 95\% CI: 1.003-1.04). When early weight change was entered into the models, the initial predictors were still significant. Early weight change at week 2 predicted successful outcome in both women (OR: 1.59, 95\% CI: 1.24 2.04 ) and men (OR: 2.15, 95\% CI: 1.38-2.35).

\section{Predictors of Attrition (III)}

Attrition rates did not differ between women and men (16 versus $19 \%, p=0.61)$. Table 4 shows baseline characteristics and HRQL stratified by attrition. Female drop-outs, as compared to completers, had a higher body weight $(\mathrm{p}<0.05)$, more obesity-related psychosocial problems $(\mathrm{p}<0.05)$, a lower frequency of having 2 or more prescribed drugs $(\mathrm{p}<$ $0.01)$ and obesity-related medication $(\mathrm{p}<0.01)$. As compared to completers, male drop-outs had a worse perceived physical health $(\mathrm{p}<0.05)$. Drop-out in women was predicted by lower age (OR: 0.92, 95\% CI: 0.88-0.97) and larger hip circumference (OR: 1.03, 95\% CI: 1.001-1.07). Hip circumference was larger than $116 \mathrm{~cm}$ in all the 29 female drop-outs compared to $84 \%$ of the completers $(\mathrm{p}<0.05)$. Attrition in men was predicted by lower perceived general health (SF-36 General health) (OR: $0.97,95 \%$ CI: 0.94-0.99). Of the 17 male drop-outs, $65 \%$ scored $\leq 50$ on general health compared to $22 \%$ among completers $(\mathrm{p}<0.01)$. When early weight change was entered into the models, it did not predict attrition in women. In men, lower weight loss at week 2 predicted attrition (OR: $0.57,95 \%$ CI: $0.35-0.92$ ), and the original predictor remained significant in the model.

\section{Discussion}

We explored predictors of treatment outcome after a 12-week VLED in 267 obese subjects. A few previous studies have reported either on predictors for long-term outcome after an initial VLED [17, 20, 21, 32], or on a limited number of variables in relation to VLED outcome [14]. To our knowledge, this is the first study that has evaluated a broad range of possible predictors for outcome of the actual VLED period in women and men separately.

In men, self-assessed walking capacity predicted both relative weight loss and successful outcome, while in women ambulatory capacity had no predictive value. Previous studies have either found no correlation between ambulatory capacity and weight loss or a positive correlation with weight maintenance $[2,33,34]$. 
Better perceived physical health was a positive predictor of $\%$ weight loss in women and completing VLED treatment in men. Higher initial ratings of physical health were also associated with larger weight loss in a study of women participating in a 6-month lifestyle intervention program [35]. In contrast, perceived pre-treatment physical health was not associated with weight change after 16 months in women participating in a 16-week weight loss program [36]. However, women in the latter study had a considerably lower mean BMI $\left(31 \mathrm{~kg} / \mathrm{m}^{2}\right)$ than women in the present study $\left(41 \mathrm{~kg} / \mathrm{m}^{2}\right)$. Thus, it is possible that better perceived physical health predicts weight loss in severely obese women with a high degree of illnesses but not in groups of overweight/moderately obese women. It is possible that severely obese patients who perceive their physical health as poor find it more difficult to cope with the low energy level and potential side effects of VLED and therefore have a poorer outcome in our study. This indicates that patients with low perceived health may need extra support during VLED treatment.

In men, cohabitation predicted relative weight change, while in women having more children similarly predicted relative weight change. Taken together, these two variables might indicate that a close family network is of importance during VLED treatment. Cohabitation also predicted greater weight loss in a sample of low-income mothers of young children participating in an 8-week weight loss program [37]. However, a review of psychosocial predictors of weight loss found no evidence that social support measured before weight loss treatment is a general determinant of weight outcome [15]. On the other hand, a recent review of factors associated with weight loss maintenance and weight regain found that social support may be beneficial from a weight maintenance point of view [34].

In men, a high frequency of ice-cream snacking predicted weight loss. It may be speculated that this variable reflects a preference for sweet, milky drinks. Men who like ice cream may find the taste and consistency of VLED more acceptable, and hence be more compliant. Frequency of ice cream snacking was assessed by a single question with a 5-point response format. We asked about snacking frequency for 5 different groups of snack food but only ice cream was an independent predictor of weight loss in men. This finding needs to be confirmed in other studies.

A total of $17 \%$ of the participants dropped out before week 12 in our study. This could be compared to $13 \%$ dropout from a 12-week VLED in a similar study group, although a 2-week run-in period was used for selection of compliant participants in that study [12]. In our study, younger women with large hip circumferences were more prone to drop-out. We have previously reported higher drop-out rates in younger patients from VLED programs with 1-4 years of follow-up $[19,21,23]$. The reason for a higher drop-out among women with larger hip circumference is less clear. Disappointment with treatment effect has been reported as a common cause for drop-out [38] and it is possible that women with large hips find it more difficult to lose weight due to the lower weight loss response in fat tissue of the femoral region as compared to the abdominal region [39]. However, hip circumference was not related to weight loss in those who completed the 12week VLED, and early weight loss did not predict attrition in women.

Successful outcome in women was predicted by less psychosocial dysfunction. Both non-successful and successful women scored very high on the OP scale, indicating severely impaired psychosocial functioning in everyday life. In men, obesity-related problems seemed to lack predictive power, probably because they had lower scores than women. In male patients, however, a better functioning in social interaction predicted successful outcome, possibly mirroring the association between psychosocial problems and success in women.

In accordance with previous studies [17, 32, 40], early weight loss was a strong predictor of final outcome in both women and men. Although not a pre-treatment predictor the early weight loss could be used and tested as a signal for more intensive support during VLED or change of treatment strategy.

It should be pointed out that this study is limited by its exploratory nature, and more work is needed to confirm the identified predictors. Another weakness of this study is that patients could select among VLED products with different energy levels. However, VLED energy level (470$560 \mathrm{kcal}$ vs. $820 \mathrm{kcal}$ ) did not predict treatment outcome, indicating that compliance to the diet may be more important than type of VLED in determining outcome. The study is also limited by the fact that changes in self-assessed eating behavior and mood were not measured during treatment. Finally, the high degree of illness in our patient group may limit the generalizability of the results to less obese, healthier patients with better quality of life. The strengths of the present study should also be noted. The relatively large proportion of men included in the study made it possible to evaluate outcome predictors stratified by gender. Results clearly indicate that different factors may influence the outcome of VLED treatment in women and men. Our results imply that conclusions about VLED predictors from studies in women cannot be generalized to men and vice versa.

In conclusion, obese women and men attained similar outcome in terms of \% weight loss, rates of success, and attrition. However, the predictors of VLED outcome differed by gender. Ambulatory capacity and social interaction seem to be important predictors for VLED outcome in men. In women, psychosocial variables should be further explored to find better predictive models, while in men prospective trials should be undertaken to evaluate the proposed predictive model. 


\section{Acknowledgments}

We want to thank the staff at the Obesity Unit at Sahlgrenska University Hospital for their committed work with this study. We also thank Karin Lantz and Margareta Rystedt for their excellent assistance with collating data. This work was supported by grants from the Swedish Foundation for Strategic Research to the Sahlgrenska Center for Cardiovascular and Metabolic Research, and The Health and Medical Care Committee of the Region Västra Götaland.

\section{Supplementary Material}

Supplementary material is available online at www.karger.com/ofa.

\section{Disclosure}

The authors declared no conflict of interest.

\section{References}

1 SCOOP-VLCD Task 7.3. Reports on tasks for scientific cooperation. Collection of data on products intended for use in very-low-calorie-diets. 2002

2 Kaukua J, Pekkarinen T, Sane T, Mustajoki P. Health-related quality of life in obese outpatients losing weight with very-low-energy diet and behaviour modification - a 2-y follow-up study. Int J Obes Relat Metab Disord 2003;27:1233-41.

3 Dhindsa P, Scott AR, Donnelly R: Metabolic and cardiovascular effects of very-low-calorie diet therapy in obese patients with Type 2 diabetes in secondary failure: outcomes after 1 year. Diabet Med 2003;20:319-24.

4 Martin CK, O'Neil PM, Pawlow L: Changes in food cravings during low-calorie and very-low-calorie diets. Obesity (Silver Spring) 2006;14:115-21.

5 Heymsfield SB, Harp JB, et al.: Why do obese patients not lose more weight when treated with low-calorie diets? A mechanistic perspective. Am J Clin Nutr 2007;85:346-54.

6 Westerterp-Plantenga MS, Lejeune MP, et al.: High protein intake sustains weight maintenance after body weight loss in humans. Int J Obes Relat Metab Disord 2004;28:57-64.

7 Anderson JW, Conley SB, Nicholas AS: One hundred pound weight losses with an intensive behavioral program: changes in risk factors in 118 patients with long-term follow-up. Am J Clin Nutr 2007;86: 301-7.

8 Rössner S, Flaten H: VLCD versus LCD in longterm treatment of obesity. Int J Obes Relat Metab Disord 1997;21:22-6.

$\checkmark$ Moreno O, Meoro A, et al.: Comparison of two low-calorie diets: a prospective study of effectiveness and safety. J Endocrinol Invest 2006:29:633-40.

-10 Foster GD, Wadden TA, et al.: A controlled comparison of three very-low-calorie diets: effects on weight, body composition, and symptoms. Am J Clin Nutr 1992;55:811-7.

11 Mathus-Vliegen EM: Long-term maintenance of weight loss with sibutramine in a GP setting following a specialist guided very-low-calorie diet: a double-blind, placebo-controlled, parallel group study. Eur J Clin Nutr 2005;59(suppl 1):S31-8; discussion S39.

12 Ryttig KR, Rössner S: Weight maintenance after a very low calorie diet (VLCD) weight reduction period and the effects of VLCD supplementation. A prospective, randomized, comparative, controlled long-term trial. J Intern Med 1995;238:299-306.

13 Colles SL, Dixon JB, et al.: Preoperative weight loss with a very-low-energy diet: quantitation of changes in liver and abdominal fat by serial imaging. Am J Clin Nutr 2006;84:304-11.
14 LaPorte DJ, Stunkard AJ: Predicting attrition and adherence to a very low calorie diet: a prospective investigation of the eating inventory. Int J Obes 1990;14:197-206.

15 Teixeira PJ, Going SB, et al.: A review of psychosocial pre-treatment predictors of weight control Obes Rev 2005;6:43-65.

16 Anderson JW, Konz EC, et al.: Long-term weightloss maintenance: a meta-analysis of US studies. Am J Clin Nutr 2001;74:579-84.

17 Stotland SC, Larocque M: Early treatment response as a predictor of ongoing weight loss in obesity treatment. Br J Health Psychol 2005;10: 601-14.

18 Astrup A, Rössner S: Lessons from obesity management programmes: greater initial weight loss improves long-term maintenance. Obes Rev 2000;1: 17-9.

19 Torgerson JS, Ågren L, Sjöström L: Effects on body weight of strict or liberal adherence to an initial period of VLCD treatment. A randomised, one-year clinical trial of obese subjects. Int J Obes Relat Metab Disord 1999:23:190-7.

20 Torgerson JS, Lissner L, et al.: VLCD plus dietary and behavioural support versus support alone in the treatment of severe obesity. A randomised two-year clinical trial. Int J Obes Relat Metab Disord 1997;21:987-94.

21 Lantz H, Peltonen M, et al.: Intermittent versus on-demand use of a very low calorie diet: a randomized 2-year clinical trial. J Intern Med 2003;253: 463-71.

22 Gripeteg L, Torgerson J, et al.: Prolonged refeeding improves weight maintenance after weight loss with very-low-energy diets. Br J Nutr 2010;103: $141-8$.

23 Lantz H, Peltonen M, et al.: A dietary and behavioural programme for the treatment of obesity. A 4-year clinical trial and a long-term posttreatment follow-up. J Intern Med 2003;254:272-9.

24 Karlsson J, Persson LO, et al.: Psychometric properties and factor structure of the Three-Factor Eating Questionnaire (TFEQ) in obese men and women. Results from the Swedish Obese Subjects (SOS) study. Int J Obes Relat Metab Disord 2000;24:1715-25.

25 Tholin S, Rasmussen F, et al.: Genetic and environmental influences on eating behavior: the Swedish Young Male Twins Study. Am J Clin Nutr 2005;81: $564-9$
6 Angle S, Engblom J, et al.: Three factor eating questionnaire-R18 as a measure of cognitive restraint, uncontrolled eating and emotional eating in a sample of young Finnish females. Int J Behav Nutr Phys Act 2009;6:41.

27 Taft C, Karlsson J, SullivanM: Performance of the Swedish SF-36 version 2.0. Qual Life Res 2004;13: 251-6.

28 Karlsson J, Sjöström L, Sullivan M: The Obesityrelated Functioning scale (OF) - development of a condition-specific functioning limitations module. Qual Life Res 2000;9:323.

29 Karlsson J, Taft C, et al.: Psychosocial functioning in the obese before and after weight reduction: construct validity and responsiveness of the Obesity-related Problems scale. Int J Obes Relat Metab Disord 2003;27:617-30.

30 Sjöberg L, Svensson E, Persson LO: The measurement of mood. Scand J Psychol 1979;20:1-18.

31 Rosenberg M: Conceiving the Self. New York, NY, Basic Books, 1979.

32 Fogelholm M, Kukkonen-Harjula K, Oja P: Eating control and physical activity as determinants of short-term weight maintenance after a very-lowcalorie diet among obese women. Int J Obes Relat Metab Disord 1999;23:203-10.

33 Karlsson J, Hallgren P, et al.: Predictors and effects of long-term dieting on mental well-being and weight loss in obese women. Appetite 1994;23:15-26.

34 Elfhag K, Rössner S: Who succeeds in maintaining weight loss? A conceptual review of factors associated with weight loss maintenance and weight regain. Obes Rev 2005;6:67-85.

35 Carels RA, Cacciapaglia HM, et al.: The early identification of poor treatment outcome in a women's weight loss program. Eat Behav 2003:4:265-82.

36 Teixeira PJ, Going SB, et al.: Pretreatment predictors of attrition and successful weight management in women. Int J Obes Relat Metab Disord 2004;28:1124-33.

37 Clarke KK, Freeland-Graves J, et al.: Predictors of weight loss in low-income mothers of young children. J Am Diet Assoc 2007;107:1146-54.

38 Grossi E, Dalle Grave R, et al.: Complexity of attrition in the treatment of obesity: clues from a structured telephone interview. Int J Obes (Lond) 2006;30:1132-7.

39 Smith U, Hammersten J, et al.: Regional differences and effect of weight reduction on human fat cell metabolism. Eur J Clin Invest 1979;9:327-32.

40 Wadden TA, Foster GD, et al.: Clinical correlates of short- and long-term weight loss. Am J Clin Nutr 1992;56(1 suppl):271S-274S. 